\title{
The Effect of $1 \mu \mathrm{g} / \mathrm{kg}$ Dexmedetomidine Combined with High-Volume/ Low-Concentration Caudal Ropivacaine in Children Undergoing Ambulatory Orchiopexy
}

\author{
Jang Eun Cho, ${ }^{a}$ Ji Young Kim, ${ }^{b}$ Sang Jae Park, ${ }^{a}$ and Hae Keum Kil*,b \\ ${ }^{a}$ Department of Anesthesiology and Pain Medicine, Korea University College of Medicine, Anam Hospital; 73 \\ Inchon-ro, Seongbuk-gu, Seoul 136-705, Republic of Korea: and ${ }^{b}$ Department of Anesthesiology and Pain Medicine, \\ Severance Hospital, Anesthesia and Pain Research Institute, Yonsei University College of Medicine; 50 Yonsei-ro, \\ Seodaemun-gu, Seoul 120-752, Republic of Korea. \\ Received January 24, 2015; accepted April 2, 2015
}

When local anesthetics are used, the administration of dexmedetomidine (DEX) can prolong analgesic duration. However, the effect of caudal DEX on high volume/low concentration (HVLC) local anesthetics has not been studied. We investigated the analgesic effect of DEX added to a HVLC of ropivacaine for caudal block in children. Eighty children (the American Society of Anesthesiologists (ASA) status I; age, 1-6 years) undergoing ambulatory orchiopexy were enrolled in the study. Children were randomly assigned to undergo a caudal block with $1.5 \mathrm{~mL} / \mathrm{kg}$ of $0.15 \%$ ropivacaine and either $1 \mu \mathrm{g} / \mathrm{kg}$ of DEX (DEX group, $n=40)$ or the same amount of saline (Control group, $n=40$ ) under general anesthesia. The results showed that the time to first analgesic request was significantly longer in the DEX group than in the control group. The sevoflurane requirement for anesthesia and frequency of emergence agitation (EA) were also significantly lower in the DEX group. There was no difference in adverse events between the two groups. In conclusion, a dose of $1 \mu \mathrm{g} /$ $\mathrm{kg}$ of caudal DEX prolonged the first analgesic request time, although the immediate postoperative pain scores were comparable in both groups. Furthermore, caudal DEX significantly reduced the sevoflurane requirement and the frequency of EA.

Key words dexmedetomidine; caudal block; child; orchiopexy

Caudal block is common method for postoperative analgesia in children undergoing infra-umbilical surgery. One major limitation of caudal block is a relatively short analgesic duration owing to the single-injection. Thus, adjuvants such as ketamine, clonidine, or opioids are frequently added to the local anesthetics in order to improve analgesic efficacy and duration. ${ }^{1,2)}$ The effectiveness of local anesthetics using in caudal block is dependent upon the dose, volume, and concentration of the local anesthetic solution, but high-concentration local anesthetics can increase the incidence of motor weakness, delayed micturition, or urinary retention. In children undergoing ambulatory surgery, such adverse effects can prolong the discharge time and may result in inadvertent admission. Recently, high-volume/low-concentration (HVLC) regimens for caudal blocks in children $(1.5 \mathrm{~mL} / \mathrm{kg}$ of $0.1-0.2 \%$ local anesthetics) have gained popularity following a report by Silvani et al. that demonstrated that a HVLC regimen provides a longer analgesic duration with less adverse effects than conventional dose/concentration. ${ }^{3-8)}$ However, the analgesic duration is still limited in caudal block with single-injection.

Dexmedetomidine (DEX) is a highly selective $\alpha_{2}$ adrenoceptor agonist with an $\alpha 2 / \alpha 1$ selectivity ratio of $1600: 1$, and is eight times more potent than clonidine.9) DEX is successfully used as an adjuvant in caudal blocks for children in order to reduce pain without inducing any significant respiratory and hemodynamic effects. Several studies have reported that in children, caudal DEX $(1-2 \mu \mathrm{g} / \mathrm{kg})$ with $0.25 \%$ bupivacaine $(1 \mathrm{~mL} / \mathrm{kg})$ prolongs postoperative analgesic duration by $2.5-3$ fold compared with a bupivacaine alone..$^{10-13)}$ However, there is no report that examines the effect of DEX in combination with HVLC local anesthetics.
We designed this randomized and double blind study to assess the analgesic effects of $1 \mu \mathrm{g} / \mathrm{kg}$ caudal DEX on HVLC ropivacaine $(0.15 \%, 1.5 \mathrm{~mL} / \mathrm{kg})$ when administered together in children undergoing orchiopexy.

\section{METHODS}

This study was approved by the Institutional Review Board of Severance Hospital (4-2011-0111) and registered at www. Clinicaltrials.gov (NCT02163980). After obtaining written informed consent from the parents, 80 children (the American Society of Anesthesiologists (ASA) status I, age 1-6 years) undergoing ambulatory unilateral orchiopexy were enrolled in the study. The exclusion criteria were developmental delay or mental retardation, neuromuscular or psychiatric disorders, coagulopathy, allergy to the study drugs, or infection at the site of the caudal block.

The patients were allocated into the DEX group $(n=40)$ or the Control group $(n=40)$ using a computer-generated randomization method conducted in the pre-anesthesia room. The drug solutions of $1.5 \mathrm{~mL} / \mathrm{kg}$ of $0.15 \%$ ropivacaine with either $1 \mu \mathrm{g} / \mathrm{kg}$ dexmedetomidine (Precedex, Hospira Inc., Lake Forest, IL, U.S.A.) or the same amount of saline were prepared in syringes and coded as A or B by nurses who were not participating in the study. The drug solution was delivered to the anesthesia provider prior to the caudal puncture. All anesthetic practitioners and postoperative investigators were blinded to the medication groups.

The children were transferred to the operating room while accompanied by one of their parents. After the application of hemodynamic and bispectral index (BIS) monitors, anesthesia 
was induced using 6-7\% sevoflurane administered via a facemask, and intravenous (i.v.) access was secured. Endotracheal intubation was performed without a neuromuscular blocker. The patients were placed in the lateral decubitus position and a caudal block was performed using a $22 \mathrm{G}$ caudal needle. Successful needle placement was confirmed with ultrasound, and the prepared drug solution was injected slowly. Anesthesia was maintained with sevoflurane in oxygen. The inspired sevoflurane concentration was adjusted to maintain a BIS score of $45-55$ and a mean arterial blood pressure (MAP) within $20 \%$ of the baseline values.

The MAP, heart rate (HR) and end-tidal sevoflurane (EtSevo) concentration were recorded every $5 \mathrm{~min}$ until the completion of surgery. We planned to administer ephedrine or atropine as needed if the MAP or HR decreased by $>20 \%$ of the baseline value. No additional analgesics or antiemetics were given during the surgery.

After completing the surgery, the tracheal tube was removed once the children awakened. In an ambulatory postanesthesia care unit (PACU), an experienced nurse who was blinded the study evaluated the pain scores at arrival, $30 \mathrm{~min}$, $1 \mathrm{~h}, 2 \mathrm{~h}$, and $3 \mathrm{~h}$ using the Face, Legs, Activity, Cry, Consolability scale (FLACC) ${ }^{14)}$ and the Children's Hospital of Eastern Ontario Pain Scale (CHEOPS). ${ }^{15)}$ The degree of sedation was assessed at arrival and $30 \mathrm{~min}$ of PACU using a three-point objective score $^{15)}(0=$ eyes open spontaneously, $1=$ eyes open in response to verbal stimulation, $2=$ eyes open in response to physical stimulation). Emergence agitation (EA) was also evaluated at arrival and $30 \mathrm{~min}$ of PACU using a modified four-point scale by Watcha et al. ${ }^{16)}(1=$ calm, $2=$ crying, but can be consoled, $3=$ crying and cannot be consoled, $4=$ agitated and thrashing around). Children with a score of $3 / 4$ were considered to be having an EA episode. If a child fell asleep, the state was defined as 0 . When children showed CHEOPS or FLACC scores $\geq 4,0.5 \mu \mathrm{g} / \mathrm{kg}$ of fentanyl was administered. Any other adverse events and the discharge time were also evaluated. While the children were in PACU, they were accompanied by their parents.

Prior to discharge, all parents were instructed on how to assess the pain scores (numerical rating scales from 0 to 10 ), when to give oral analgesics, and how to record this. They were instructed to give oral acetaminophen if the child's pain score was 4 or greater. Information regarding the analgesia was obtained via telephone interview by a blinded investigator at $24 \mathrm{~h}$ after surgery.

Statistical Analysis The primary end-point of this current study was to compare the time to the first oral acetaminophen request after discharge between the two groups. On the basis of previous studies, ${ }^{4,9,11,12,17)}$ we determined that 32 patients would be required in each group with an $\alpha$ level of 0.05 and power of $90 \%$ to detect a $10 \mathrm{~h}$ difference in time to the first analgesic request between the groups. Forty children were enrolled in each group to allow for a potential 20\% drop-out.

Data were analyzed using IBM SPSS Statistics $19^{\mathrm{TM}}$ (SPSS Inc., Chicago, IL, U.S.A.). Normality of distribution was assessed with a q-q plot and the Shapiro-Wilk test. Parametric data was analyzed using the independent $t$-test and repeated ANOVA measures followed by the post hoc Dunnett's test. Non-parametric data were compared using the Mann-Whitney $U$ test, the Wilcoxon rank-sum test, and the Friedman test,

Table 1. Patient Characteristics and Intraoperative Data

\begin{tabular}{lcc}
\hline \hline & Control group $(n=40)$ & DEX group $(n=40)$ \\
\hline Age (months) & $21.4(3-53)$ & $22.6(2-71)$ \\
Body weight $(\mathrm{kg})$ & $11.7(3.4)$ & $12.4(3.5)$ \\
Height $(\mathrm{cm})$ & $71.2(21.1)$ & $82.1(14.1)$ \\
Duration of surgery (min) & $40.2(27.3)$ & $45.2(28.0)$ \\
Awakening time (min) & $8.9(3.7)$ & $8.2(2.6)$ \\
Fluid intake $(\mathrm{mL})$ & $73.6(57.8)$ & $53.7(58.4)$ \\
\hline
\end{tabular}

Data are shown as mean \pm S.D

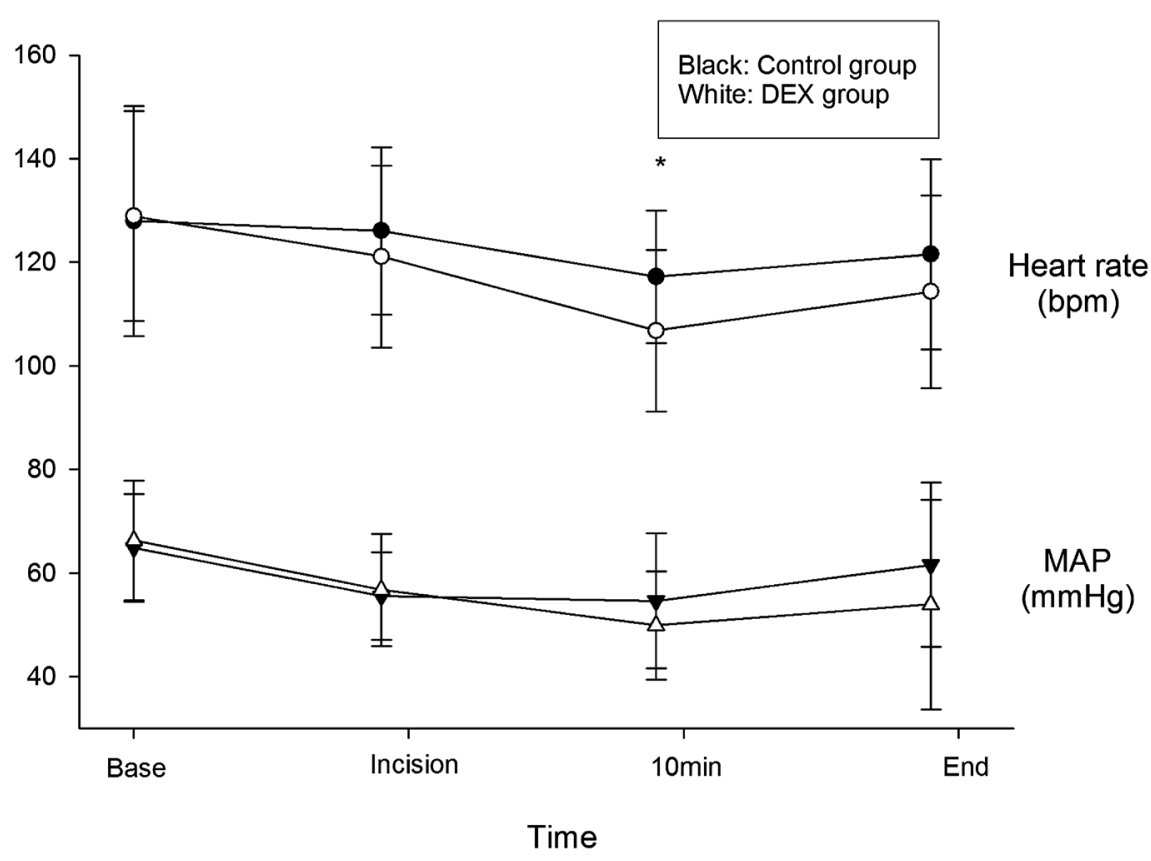

Fig. 1. HR and MAP during Surgery

Base, baseline values before caudal block; Incision, value after surgical incision; $10 \mathrm{~min}$, value $10 \mathrm{~min}$ after incision; End, value at the end of surgery. ${ }^{*} p<0.05$. 
with a Bonferroni correction between and within the groups. Frequencies were evaluated using the chi-square and Fisher's exact test. A Kaplan-Meier survival curve was obtained for the time to the first analgesic requirement during the $24 \mathrm{~h}$ post discharge. Values are presented as the mean ( \pm standard deviation (S.D.)). A $p$-value of $<0.05$ was considered statistically significant.

\section{RESULTS}

Eighty male children completed this study (Control group, $n=40$; DEX group, $n=40$ ). There were no differences in patients' characteristics between the two groups (Table 1).

The HR was significantly reduced at $10 \mathrm{~min}$ of surgery in the DEX group compared with the Control group $(p=0.007)$, but MAP changes were similar in both groups (Fig. 1). The Et-Sevo concentration was significantly lower in the DEX group compared with the control group during anesthesia (Fig.

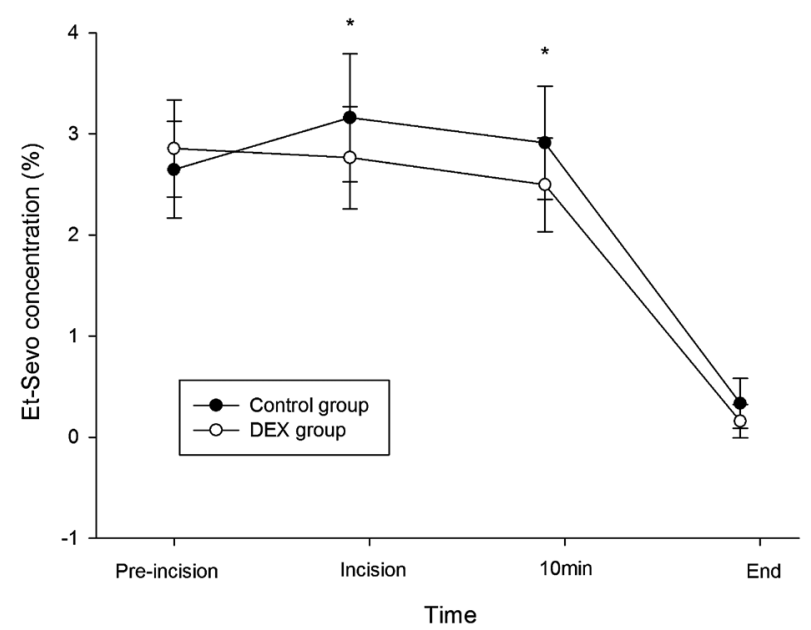

Fig. 2. End-Tidal Sevoflurane (Et-Sevo) Concentration during Surgery

Pre-incision, value before surgical incision; Incision, value after surgical incision; $10 \mathrm{~min}$, value $10 \mathrm{~min}$ after iincision; End, value at the end of surgery. $* p<0.05$.
2).

During the postoperative period, the FLACC pain score was lower in the DEX group than in the control group at $30 \mathrm{~min}$ of PACU (Fig. 3A). The DEX group demonstrated a significantly lower frequency of EA and a higher sedation score at arrival and after $30 \mathrm{~min}$ in PACU. The discharge time was comparable in both groups (Table 2). No differences in adverse events were noted between the two groups during recovery.

After discharge, the time to the first analgesic request was significantly longer in the DEX group compared with the Control group (Table 2, Fig. 4). However, the frequency of analgesic requirement was not significantly different $(p=0.058)$. There were no adverse events related to surgical wound and general condition in all children for the study period.

\section{DISCUSSION}

This is the first study to compare the effect of caudal DEX with HVLC ropivacaine on postoperative analgesia in children. In this study, we used $1 \mu \mathrm{g} / \mathrm{kg}$ of DEX with ropivacaine for caudal block based on a study by Saadawy et al. ${ }^{12)}$ The primary endpoint of this study was time to first rescue analgesics request by subjects in the DEX and the control groups. In this current study, $1 \mu \mathrm{g} / \mathrm{kg} \mathrm{DEX}$, compared to HVLC alone, was effective in prolonging the analgesic duration by 1.4 -fold (11.8h vs. 8.5 h).

$\alpha_{2}$-Adrenoceptor-induced antinociception is mediated by an inhibition of synaptic transmission within the dorsal horn of the spinal cord. ${ }^{18)}$ DEX has a greater binding affinity for $\alpha_{2}$-adrenoceptors in the spinal cord than in brain. ${ }^{19)}$ Thus, the relative antinociceptive potency of extradural DEX may depend on the binding affinity to $\alpha_{2}$-adrenoceptors in the spinal cord. ${ }^{19)}$ As the sacral region has the largest concentration of $\alpha_{2}$-adrenoceptors than the lumbar or thoracic regions in humans, ${ }^{20,21)}$ caudally administered DEX combined with local anesthetics could provide effective analgesia. In this current study, although the analgesic duration was shorter than that in other studies that used a higher concentration $(0.25 \%)$ of bupivacaine ${ }^{4,10-13)}$ or ropivacaine, ${ }^{17)}$ the analgesic duration
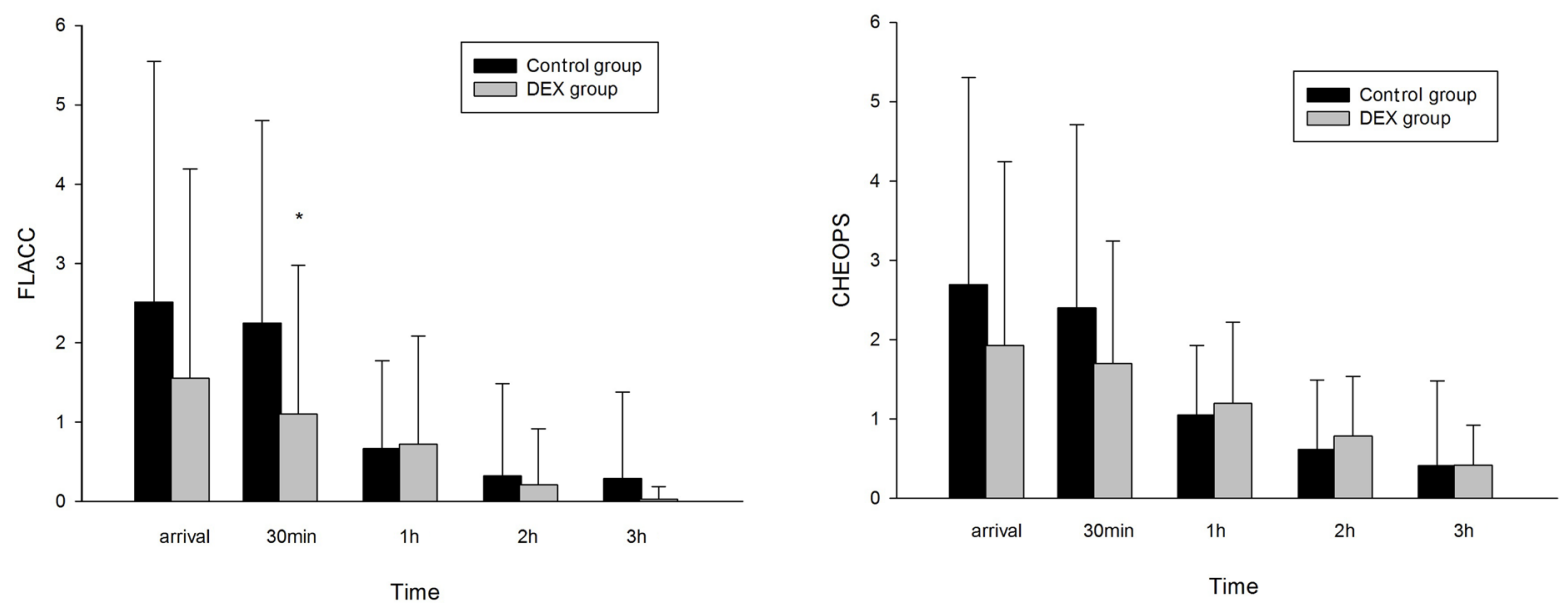

Fig. 3. Pain Scores during the $3 \mathrm{~h}$ Postoperative Period

FLACC (Face, Legs, Activity, Cry, Consolability scale); CHEOPS (Children's Hospital of Eastern Ontario Pain Scale); arrival, value at the arrival in post anesthetic care unit; $30 \mathrm{~min}$, value at postoperative $30 \mathrm{~min} ; 1 \mathrm{~h}$, value at postoperative $1 \mathrm{~h} ; 2 \mathrm{~h}$, value at postoperative $2 \mathrm{~h} ; 3 \mathrm{~h}$, value at postoperative $3 \mathrm{~h}$. ${ }^{*} p<0.05$. 
Table 2. Postoperative Characteristics

\begin{tabular}{|c|c|c|c|}
\hline & Control group $(n=40)$ & DEX group $(n=40)$ & $p$-Value \\
\hline \multicolumn{4}{|l|}{ In PACU } \\
\hline \multicolumn{4}{|l|}{ Emergence agitation } \\
\hline Arrival & $18(45 \%)$ & $3(7.5 \%)^{\dagger}$ & $<0.001$ \\
\hline $30 \mathrm{~min}$ & $7(17.5 \%)$ & $4(10 \%)$ & 0.116 \\
\hline \multicolumn{4}{|l|}{ Sedation score } \\
\hline Arrival & $0.9(0.9)$ & $1.5(0.8)$ & 0.296 \\
\hline $30 \mathrm{~min}$ & $0.2(0.5)$ & $1.1(0.9)^{*}$ & 0.004 \\
\hline Rescue fentanyl & 1 & 2 & 1.000 \\
\hline Vomiting & 1 & 1 & 1.000 \\
\hline Motor weakness & 0 & 1 & 1.000 \\
\hline Discharge time (min) & $226.9(53.3)$ & $228.6(55.0)$ & 0.767 \\
\hline \multicolumn{4}{|l|}{ After discharge } \\
\hline Time to first acetaminophen (min) & $521.2(235-960)$ & $707.1(380-1320)^{*}$ & 0.015 \\
\hline Number of patients & $22(55 \%)$ & $14(35 \%)$ & 0.058 \\
\hline
\end{tabular}

Data are shown as mean \pm S.D., median (range) or number (\%). PACU (post-anesthetic care unit). ${ }^{*} p<0.05,{ }^{\dagger} p<0.001$

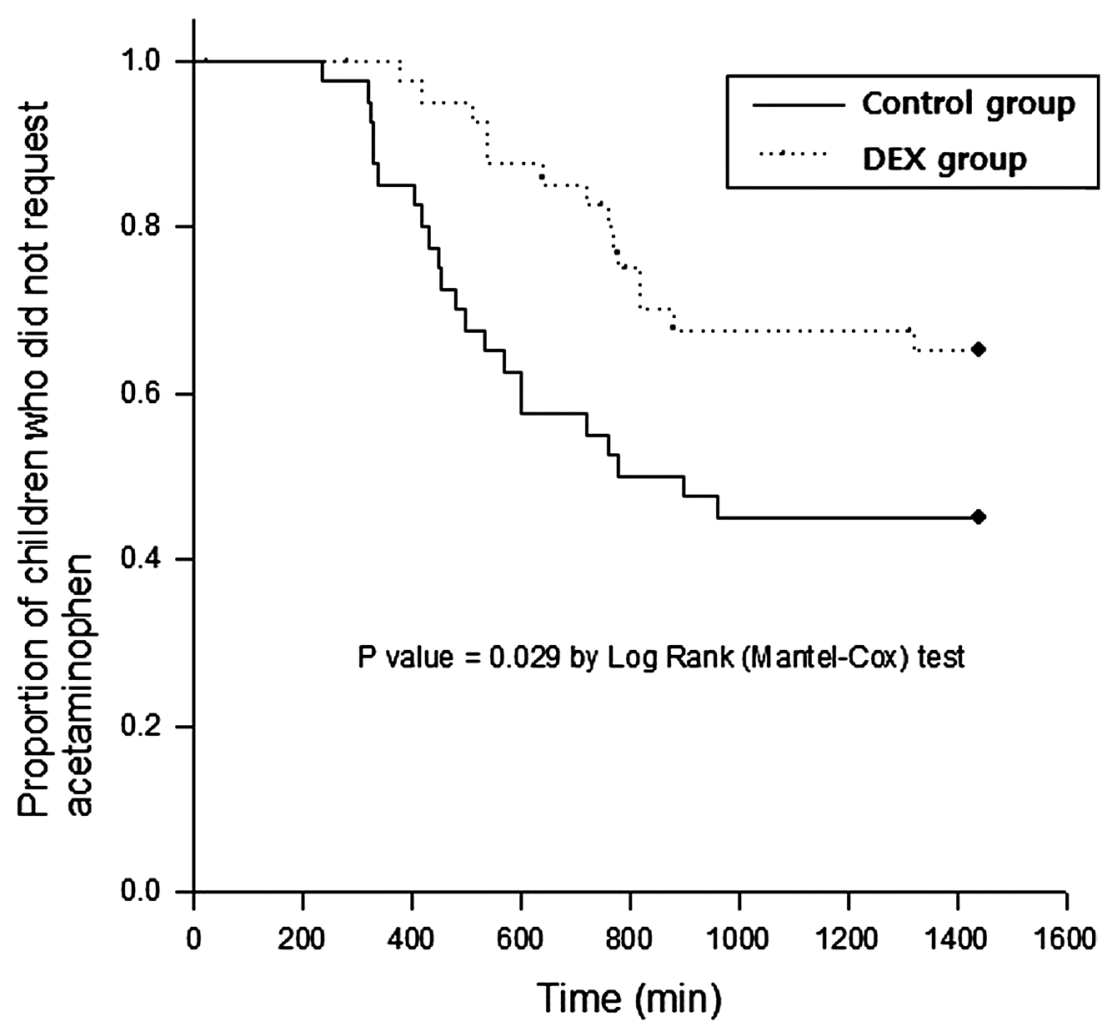

Fig. 4. Kaplan-Meier Curve for the Time to the First Analgesic Request

The proportion of the patients who did not request oral acetaminophen was significantly higher in the DEX than in Control group ( $p=0.029)$.

was significantly longer in DEX group than in control group. This result is not consistent with the results of the studies that used clonidine $(2 \mu \mathrm{g} / \mathrm{kg})$ with a low concentration $(0.125 \%)$ of bupivacaine $(1 \mathrm{~mL} / \mathrm{kg})$, in which analgesic efficacy was not significantly improved. ${ }^{22-24)}$ The authors of those studies speculated that clonidine $2 \mu \mathrm{g} / \mathrm{kg}$ may not be effective with a lowconcentration of bupivacaine, although the exact mechanism is unclear. However, DEX is a more selective $\alpha 2$-adrenoceptor agonist and is eight times potent than clonidine. Thus, $1 \mu \mathrm{g} / \mathrm{kg}$ DEX can provide a prolonged analgesic duration when added to HVLC local anesthetics, as demonstrated in this current study. Additionally, caudal DEX with a low-concentration of local anesthetics induces less adverse effects (motor weakness, delayed micturition of urinary retention) that may affect early discharge from hospital, compared with a higher concentration of local anesthetics. . $^{3,4,10,12,13,23)}$

DEX has anxiolytic, sedative, and hypnotic properties caused by stimulation of the $\alpha 2$-adrenoceptor in the locus coeruleus in brain where it decreases a neuronal activation ${ }^{9,24)}$ and can reduce the requirement of concomitantly administered hypnotics, analgesics, or anesthetics. ${ }^{25}$ Intravenous DEX significantly decreases the sevoflurane requirement ${ }^{5,26}$ for anesthesia and EA during recovery. ${ }^{5,27)}$ Caudally administered DEX was also associated with a decreased sevoflurane requirement and increased the duration of postoperative sedation in children. ${ }^{12,28)}$ The sedative and analgesic properties of 
DEX might account for the anesthetic-sparing effect. ${ }^{12)}$ Our study showed a decreased sevoflurane requirement in the DEX group compared with the control group. During surgery, Et-Sevo was $22-25 \%$ lower in the DEX group than in the control group. The reduction was not as great as in a study by Saadawy et $a l .{ }^{12)}$ in which DEX was given caudally with a higher concentration $(0.25 \%)$ of bupivacaine, and anesthesia was maintained with sevoflurane in $70 \%$ nitrous oxide. Nitrous oxide is thought to mediate analgesia via $\alpha_{2 B^{-}}$and $\alpha_{2 \mathrm{~A}}$-adrenoceptor subtypes within the spinal cord, similar to dexmedetomidine. $^{29)}$ It was speculated that DEX is likely to provide enhanced analgesia with nitrous oxide. In our study, nitrous oxide was not used. Thus, the greater degree of reduced sevoflurane requirement in a study by Saadawy et al. could be explained by the effect of nitrous oxide in combination with a higher concentration of caudal bupivacaine.

DEX has advantage of reducing the frequency of EA after sevoflurane anesthesia with its analgesic and sedative effects. $^{30)}$ In our study, the frequency of EA was significantly lower in the DEX group compared with the control group (7.5\% vs. 55\%), which is similar to the results of a study by Saadawy et al. ${ }^{12)}$ The cause of EA is multifactorial, and sevoflurane has been considered to be a major factor. Although the reason for frequent EA following sevoflurane is not clear, sevoflurane may exert an irritating effect on the central nervous system. ${ }^{31,32)}$ Thus, the decreased frequency of EA may be related to the decrease in sevoflurane concentration and the sedative effect of caudal DEX. ${ }^{5,33)}$ Sedation score was relatively high in the DEX group at arrival and at $30 \mathrm{~min}$ of PACU, but comparable afterwards and the discharge time was similar in both groups. Caudally administered DEX prolongs the postoperative sedation, but it helps in reducing the parents' anxiety as the children remain calm and sedated. ${ }^{12,34)}$

DEX, $\alpha 2$-agonist, decreases the MAP and HR dose-dependently. However, these adverse effects appear to be less prominent in children compared with adults. ${ }^{12)}$ In this current study, HR decreased significantly in DEX group compared with the Control group at $10 \mathrm{~min}$ after surgical incision. Considering the surgical preparation time after caudal block, the time to decrease in HR and MAP after caudal DEX was similar to the previous studies (25-35 min after caudal block). ${ }^{10,12)} \mathrm{HR}$ was recovered to the near baseline value by the end of surgery (Fig. 1).

In conclusion, $1 \mu \mathrm{g} / \mathrm{kg}$ of DEX co-administered with $1.5 \mathrm{~mL} / \mathrm{kg}$ of $0.15 \%$ ropivacaine via the caudal route prolonged the analgesic duration in children who underwent ambulatory orchiopexy. Caudal DEX also significantly reduced the sevoflurane requirement for anesthesia and the frequency of EA.

Acknowledgment This work was supported by the Technology Innovation Program (10049743) funded by the Ministry of Trade, Industry \& Energy, Republic of Korea.

Conflict of Interest The authors declare no conflict of interest.

\section{REFERENCES}

1) Axelsson K, Gupta A. Local anaesthetic adjuvants: neuraxial versus peripheral nerve block. Curr. Opin. Anaesthesiol., 22, 649-654 (2009).
2) Lönnqvist PA. Adjuncts to caudal block in children-Quo vadis? Br. J. Anaesth., 95, 431-433 (2005).

3) Hong JY, Han SW, Kim WO, Cho JS, Kil HK. A comparison of high volume/low concentration and low volume/high concentration ropivacaine in caudal analgesia for pediatric orchiopexy. Anesth. Analg., 109, 1073-1078 (2009).

4) Kim EM, Lee JR, Koo BN, Im YJ, Oh HJ, Lee JH. Analgesic efficacy of caudal dexamethasone combined with ropivacaine in children undergoing orchiopexy. Br. J. Anaesth., 112, 885-891 (2014).

5) Kim NY, Kim SY, Yoon HJ, Kil HK. Effect of dexmedetomidine on sevoflurane requirements and emergence agitation in children undergoing ambulatory surgery. Yonsei Med. J., 55, 209-215 (2014).

6) Lundblad M, Eksborg S, Lönnqvist PA. Secondary spread of caudal block as assessed by ultrasonography. Br. J. Anaesth., 108, 675-681 (2012).

7) Lundblad M, Lönnqvist PA, Eksborg S, Marhofer P. Segmental distribution of high-volume caudal anesthesia in neonates, infants, and toddlers as assessed by ultrasonography. Paediatr. Anaesth., 21, 121-127 (2011).

8) Silvani P, Camporesi A, Agostino MR, Salvo I. Caudal anesthesia in pediatrics: an update. Minerva Anesthesiol., 72, 453-459 (2006).

9) Coursin DB, Coursin DB, Maccioli GA. Dexmedetomidine. Curr. Opin. Crit. Care, 7, 221-226 (2001).

10) El-Hennawy AM, Abd-Elwahab AM, Abd-Elmaksoud AM, ElOzairy HS, Boulis SR. Addition of clonidine or dexmedetomidine to bupivacaine prolongs caudal analgesia in children. Br. J. Anaesth., 103, 268-274 (2009).

11) Fares KM, Othman AH, Alieldin NH. Efficacy and safety of dexmedetomidine added to caudal bupivacaine in pediatric major abdominal cancer surgery. Pain Physician, 17, 393-400 (2014).

12) Saadawy I, Boker A, Elshahawy MA, Almazrooa A, Melibary S, Abdellatif AA, Afifi W. Effect of dexmedetomidine on the characteristics of bupivacaine in a caudal block in pediatrics. Acta Anaesthesiol. Scand., 53, 251-256 (2009).

13) Xiang Q, Huang DY, Zhao YL, Wang GH, Liu YX, Zhong L, Luo T. Caudal dexmedetomidine combined with bupivacaine inhibit the response to hernial sac traction in children undergoing inguinal hernia repair. Br. J. Anaesth., 110, 420-424 (2013).

14) Voepel-Lewis T, Zanotti J, Dammeyer JA, Merkel S. Reliability and validity of the face, legs, activity, cry, consolability behavioral tool in assessing acute pain in critically ill patients. Am. J. Crit. Care, 19, 55-61, quiz, 62 (2010).

15) Beyer JE, McGrath PJ, Berde CB. Discordance between self-report and behavioral pain measures in children aged 3-7 years after surgery. J. Pain Symptom Manage., 5, 350-356 (1990).

16) Watcha MF, Ramirez-Ruiz M, White PF, Jones MB, Lagueruela RG, Terkonda RP. Perioperative effects of oral ketorolac and acetaminophen in children undergoing bilateral myringotomy. Can. J. Anaesth., 39, 649-654 (1992).

17) Anand VG, Kannan M, Thavamani A, Bridgit MJ. Effects of dexmedetomidine added to caudal ropivacaine in paediatric lower abdominal surgeries. Indian J. Anaesth., 55, 340-346 (2011).

18) Sullivan AF, Kalso EA, McQuay HJ, Dickenson AH. The antinociceptive actions of dexmedetomidine on dorsal horn neuronal responses in the anaesthetized rat. Eur. J. Pharmacol., 215, 127-133 (1992).

19) Asano $T$, Dohi S, Ohta S, Shimonaka H, Iida H. Antinociception by epidural and systemic alpha(2)-adrenoceptor agonists and their binding affinity in rat spinal cord and brain. Anesth. Analg., 90, 400-407 (2000).

20) Lawhead RG, Blaxall HS, Bylund DB. Alpha-2A is the predominant alpha-2 adrenergic receptor subtype in human spinal cord. Anesthesiology, 77, 983-991 (1992).

21) Smith MS, Schambra UB, Wilson KH, Page SO, Hulette C, Light AR, Schwinn DA. Alpha 2-adrenergic receptors in human spinal cord: specific localized expression of mRNA encoding alpha(2)- 
adrenergic receptor subtypes at four distinct levels. Brain Res. Mol. Brain Res., 34, 109-117 (1995).

22) Joshi W, Connelly NR, Freeman K, Reuben SS. Analgesic effect of clonidine added to bupivacaine $0.125 \%$ in paediatric caudal blockade. Paediatr. Anaesth., 14, 483-486 (2004).

23) Sharpe P, Klein JR, Thompson JP, Rushman SC, Sherwin J, Wandless JG, Fell D. Analgesia for circumcision in a paediatric population: comparison of caudal bupivacaine alone with bupivacaine plus two doses of clonidine. Paediatr. Anaesth., 11, 695-700 (2001).

24) Nelson LE, Lu J, Guo T, Saper CB, Franks NP, Maze M. The $\alpha 2$-adrenoceptor agonist dexmedetomidine converges on an endogenous sleep-promoting pathway to exert its sedative effects. Anesthesiology, 98, 428-436 (2003).

25) Hall JE, Uhrich TD, Barney JA, Arain SR, Ebert TJ. Sedative, amnestic, and analgesic properties of small-dose dexmedetomidine infusions. Anesth. Analg., 90, 699-705 (2000).

26) Patel A, Davidson M, Tran MC, Quraishi H, Schoenberg C, Sant M, Lin A, Sun X. Dexmedetomidine infusion for analgesia and prevention of emergence agitation in children with obstructive sleep apnea syndrome undergoing tonsillectomy and adenoidectomy. Anesth. Analg., 111, 1004-1010 (2010).

27) Sato M, Shirakami G, Tazuke-Nishimura M, Matsuura S, Tanimoto K, Fukuda K. Effect of single-dose dexmedetomidine on emergence agitation and recovery profiles after sevoflurane anesthesia in pedi- atric ambulatory surgery. J. Anesth., 24, 675-682 (2010).

28) She YJ, Zhang ZY, Song XR. Caudal dexmedetomidine decreases the required concentration of levobupivacaine for caudal block in pediatric patients: a randomized trial. Paediatr. Anaesth., 23, 1205-1212 (2013).

29) Dawson C, Ma D, Chow A, Maze M. Dexmedetomidine enhances analgesic action of nitrous oxide: mechanisms of action. Anesthesiology, 100, 894-904 (2004).

30) Ibacache ME, Muñoz HR, Brabders V, Morales AL. Single-dose dexmedetomidine reduces agitation after sevoflurane anesthesia in children. Anesth. Analg., 98, 60-63 (2004).

31) Komatsu H, Taie S, Endo S, Fukuda K, Ueki M, Nogaya J, Ogli K. Electrical seizures during sevoflurane anesthesia in two pediatric patients with epilepsy. Anesthesiology, 81, 1535-1537 (1994).

32) Woodforth IJ, Hicks RG, Crawford MR, Stephen JP, Burke DJ. Electroencephalographic evidence of seizure activity under deep sevoflurane anesthesia in a nonepileptic patient. Anesthesiology, 87, 1579-1582 (1997).

33) Na HS, Song IA, Hwang JW, Do SH, Oh AY. Emergence agitation in children undergoing adenotonsillectomy: a comparison of sevoflurane vs. sevoflurane-remifentanil administration. Acta Anaesthesiol. Scand., 57, 100-105 (2013).

34) Lerman J, Lerman J. Anxiolysis-by the parent or for the parent? Anesthesiology, 92, 925-927 (2000). 